\title{
THE SEPARATION OF SERUM PIGMENTS GIVING THE DIRECT AND INDIRECT VAN DEN BERGH REACTION*
}

\author{
BY \\ P. G. COLE AND G. H. LATHE \\ From the Bernhard Baron Memorial Research Laboratories, Queen Charlotte's Maternity Hospital, London
}

(RECEIVED FOR PUBLICATION DECEMBER 16,1952 )

Forty years ago van den Bergh developed a method for the estimation of bilirubin in serum by combining it in alcoholic solution with freshly diazotized sulphanilic acid. Shortly afterwards van den Bergh and Müller (1916) noted that by the omission of alcohol they could distinguish two types of reaction. Pigments from bile and serum from cases of obstructive jaundice developed a colour in the absence of alcohol. This was called a "direct" reaction. Normal serum, and that of patients with haemolytic jaundice, required alcohol for the development of colour, and they were said to give an "indirect" reaction.

Many attempts have been made to explain the difference between the "direct" and the "indirect" reactions, but the explanations fall mainly into two groups. The first attributes the difference to the existence of two separate pigments. On the basis of clinical and physiological evidence it is considered that bilirubin is formed through the breakdown of haemoglobin. Bilirubin reacts indirectly in the van den Bergh reaction, but on passage through the parenchymal cells of the liver it is transformed into an unknown, direct-reacting pigment which appears in the bile, or in the serum when the flow of bile is obstructed. The second group considers that the difference between the two types of reaction is due to the presence of either inhibiting substances or of catalysts. Particular attention has been paid to the possible role of proteins, and it is widely held that in the indirect reaction alcohol is necessary to release bilirubin from plasma proteins to which it is bound. This fundamental uncertainty as to the nature of the van den Bergh reaction has lasted for a quarter of a century.

Recently our attention was directed to a study of the bile pigments present in kernicterus, and methods have been devised for fractionating bile pigments by "reverse phase" chromatography.

*A preliminary account of this work was given before the Biochemical Society (Biochem. J., 1953, 53, vi).
In the course of this work bile pigments have been extracted from sera of jaundiced patients, and it has been found possible to separate the direct- and indirect-reacting pigments which are characteristic of obstructive and haemolytic jaundice.

\section{Materials}

The direct van den Bergh reaction is given by sera from patients with obstructive jaundice and with hepatitis. The bile pigments of sera from four cases of obstruction due to carcinoma of the pancreas, two cases of intra-hepatic obstruction (cirrhosis), and two cases of hepatitis have been examined.

The indirect reaction is frequently given by sera from cases of haemolytic jaundice. Pigments have been extracted from the serum removed in exchange transfusions of four cases of haemolytic disease of the newborn, all attributed to $R \mathrm{~h}$ incompatibility. Only one case of adult haemolytic anaemia has been available to us.

The pigments of six specimens of human gallbladder bile, obtained at necropsy, have also been examined.

\section{Methods}

Pigments were prepared from the sera of jaundiced patients by adding, with stirring, to 1 volume of serum 0.18 volumes of saturated ammonium sulphate and 2.5 volumes of ethanol. After standing for an hour the precipitate of protein and ammonium sulphate was removed by centrifuging. The supernatant, which was stored at $-12^{\circ} \mathrm{C}$, , was taken to dryness in vacuo immediately before use.

Bile pigments were prepared from human necropsy bile by adding 4 volumes of ethanol, or 2 volumes of ethanol and 2 of methanol, after which the mixture was filtered and stored at $-12^{\circ} \mathrm{C}$. Before being used the extract was taken to dryness in vacuo.

Bile pigments were separated by "reverse phase" chromatography on columns of silicone-treated kieselguhr (Howard and Martin, 1950). This treatment enables the aqueous phase to be moved. Satisfactory separation of bile pigments may be achieved with 
phases prepared by mixing 25 volumes of chloroform, 25 volumes of carbon tetrachloride, 38 volumes of methanol, 6 volumes of water, and 6 volumes of $p \mathrm{H} 6$ phosphate buffer (Cole, 1933). The columns were run in glass tubes of $1.8 \mathrm{~cm}$. diameter containing $6 \mathrm{~g}$. of silicone-treated kieselguhr, $3 \mathrm{ml}$. of stationary, nonpolar (bottom) phase, and approximately $17 \mathrm{ml}$. of mobile, polar (top) phase.

Reagents for the van den Bergh reaction were $0.1 \%(\mathrm{w} / \mathrm{v})$ sulphanilic acid in $0.25 \mathrm{~N}-\mathrm{HCl}$ and $0.5 \%(\mathrm{w} / \mathrm{v})$ sodium nitrite. These were mixed in a ratio of 10 to 0.3 immediately before use. A methyl red standard was prepared according to King and Coxon (1950). The depth of colour of the diazo pigment was estimated in a "unicam " electrophotometer using a green filter. The depth of the yellow of undiazotized solutions was read in a Spekker colorimeter using a pair of $0.5 \mathrm{ml}$. $(1 \mathrm{~cm}$.) cells, and Ilford "spectrum violet" filters (No. 601).

\section{Separation of Pigments}

The direct- and indirect-reacting bile pigments move on the reverse phase kieselguhr columns at different rates. The first to come off is the directreacting pigment, being more soluble in the moving aqueous phase. The predominance of this pigment, with a peak at $18 \mathrm{ml}$, is shown in the chromatogram of a specimen of icteric serum from a case of obstructive jaundice (Fig. 1). Both

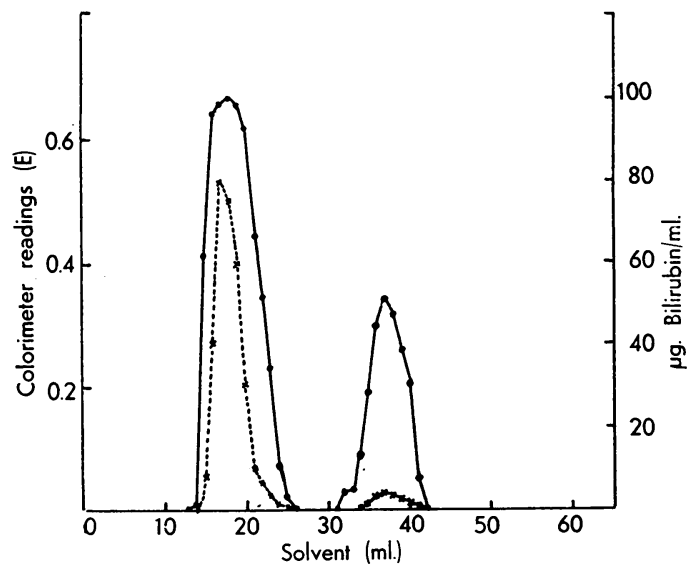

FIG. 1.-Chromatographic separation of serum pigments occurring in obstructive jaundice as shown by depth of colour (. and amount of diazo-reacting material $\left(\mathbf{x}-\mathrm{x}^{--x}\right)$ in solvent coming off the column.

the depth of the yellow and the extent of colour development after diazotization are shown. In addition to the large peak at $18 \mathrm{ml}$. a small one is seen at $37 \mathrm{ml}$. This slow-moving pigment is the main one in a typical serum from haemolytic disease of the newborn, shown in Fig. 2. In this serum there is a small amount of the fast-moving

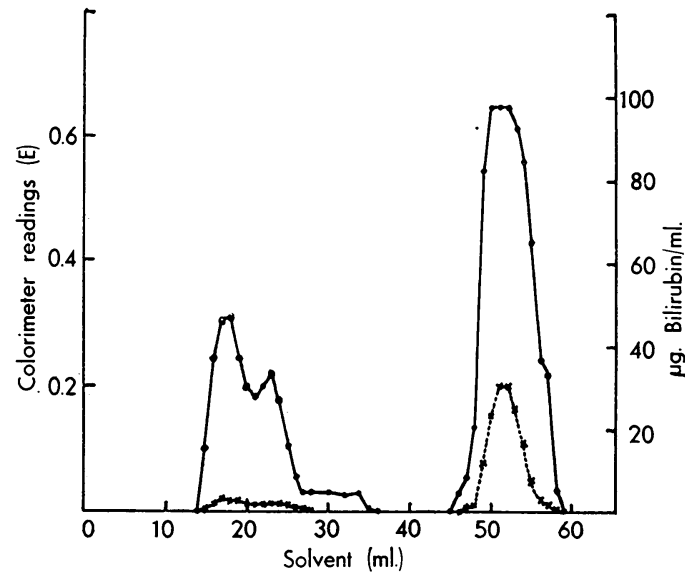

FIG. 2.-Chromatographic separation of serum pigments occurring in haemolytic jaundice as shown by depth of colour (._...) and amount of diazo-reacting material $(x---x)$ in solvent coming off the column.

pigment, with a peak at $18 \mathrm{ml}$. A large amount of slow-moving pigment, reacting indirectly, comes off between 45 and $58 \mathrm{ml}$. In the two sera from cases of hepatitis these bands appeared in more equal proportions.

For comparison a sample of pure bilirubin was put on a column. Under these conditions it appeared as a single, slow-moving band which was eluted with a peak at $26 \mathrm{ml}$., as shown in Fig. 3 . However, when added to serum it is retarded on the column, and coincides with the slow band.



FIG. 3-Chromatographic behaviour of bilirubin as shown by depth of colour (. .) and amount of diazo-reacting material $(x----x)$ in solvent coming off the column.

A demonstration of the type of the van den Bergh reaction given by these two pigments cannot be made in the solution coming off the columns, because this contains methyl alcohol in whose 
presence both types of pigment react. Nor is it sufficient to remove the solvent in vacuo and test the deposit after the addition of water. Under these conditions the fast-moving pigment dissolves and gives an immediate colour reaction. The slowmoving pigment will not dissolve in water alone and therefore gives no reaction. Alcohol takes it into solution, and then it gives an indirect van den Bergh reaction. Basically this difference in behaviour is due to the insolubility of one pigment.

In order to demonstrate the difference in reaction under the usual hospital laboratory conditions, use has been made of the ability of albumin to disperse the slow-moving pigment in an aqueous solution. However, if the eluate is first reduced to dryness the slow pigment is taken up very slowly by $3 \%$ bovine albumin solution. This difficulty can be avoided by adding an equal volume of water to some of the eluate containing the slow pigment. Two phases form, the lower of which consists of a solution of the pigment in chloroform and carbon tetrachloride. The methyl alcohol can now be removed with the aqueous phase. To the chloroform carbon tetrachloride layer is now added an equal volume of $3 \%(\mathrm{w} / \mathrm{v})$ bovine serum albumin. Finally 2 or 3 volumes of light petroleum are added, the mixture vigorously shaken, and the new layers are separated by centrifuging. The aqueous layer is now a clear yellow solution. With the fast-moving pigment this stage is reached by taking the eluate to dryness and adding water directly. In order to make the conditions entirely comparable, however, the material may be dissolved in $3 \%$ albumin.

The difference in reaction of these pigments is seen by comparing the rates of colour development on addition of the diazo reagent. In Fig. 4 the fast-moving pigment changes immediately to the characteristic purple pink of the azo-pigment, and no further deepening of colour occurs when alcohol is added at 15 minutes. This is a "direct" reaction. The behaviour of the slow-moving pigment is shown in Fig. 5. After adding the diazo reagent no significant change occurs. But alcohol produces an immediate colour development. This is a typical "indirect" reaction.

\section{Human Bile}

It was interesting to examine the pigments of bile, since it was in bile that van den Bergh and Müller (1916) first made the fortunate error of omitting alcohol from their diazotization mixture, and thus discovered that a direct reaction could take place in its absence. The way in which the

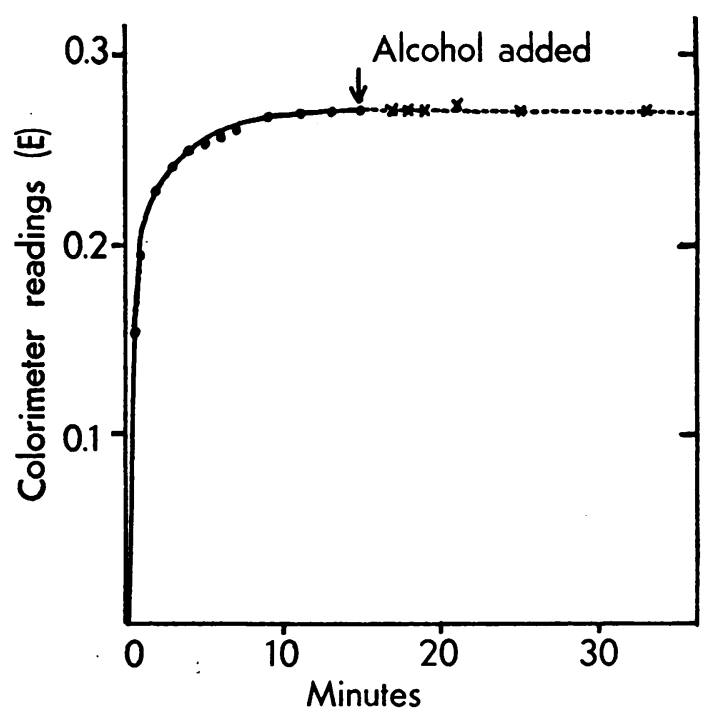

FIG. 4.-Rate of colour development by fast-moving, " direct" pigment after the addition of diazo reagents in aqueous solution at 0 minutes, as shown by colorimeter reading (._. . ) and colorimeter reading $\times 3(\mathrm{x}----\mathrm{x})$ after the addition of 2 volumes of alcohol at 15 minutes.

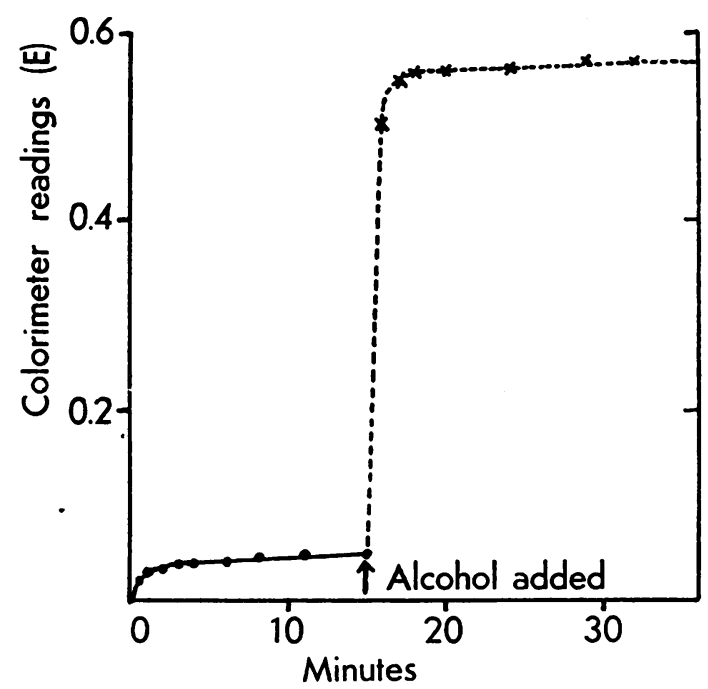

FIG. 5.-Rate of colour development by slow-moving, " indirect" pigment following addition of diazo reagents in aqueous solution at 0 minutes as shown by colorimeter reading (._. ) and colorimeter reading $\times 3(x----x)$ after the addition of 2 volumes of alcohol at 15 minutes.

pigments of a typical specimen of human necropsy bile are eluted from the column is shown in Fig. 6. It is apparent that considerable amounts of yellow pigment came off the column in the position corresponding roughly to the fast, direct-reacting pigment, and smaller amounts of the slow-moving, indirect-reacting pigment were eluted later. We 


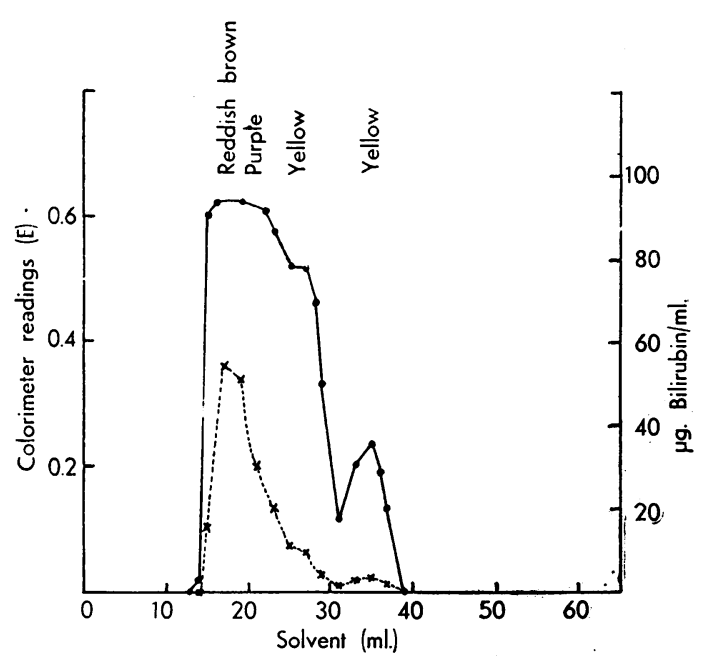

FIG. 6.-Chromatographic behaviour of human necropsy bile as shown by depth of colour (._. ) and amount of diazo-reacting material $(x---x)$ in solvent coming off the column.

have confirmed that these pigments give the appropriate van den Bergh reaction.

The curve of elution of bile pigments suggests strongly that several pigments are present, particularly in the early eluate. This is shown by the fact that before and after the diazo-reacting material there is yellow material which is diazonegative. Moreover, yellow pigments are not the only ones found. A purple pigment (peak at 21 ml.) occurred in the specimen charted, and others have shown a green band on the column.

The presence of a green pigment was not unexpected, as human necropsy bile is occasionally green, and in some animals, for example, the frog, the bile is always green. From green bile biliverdin has been isolated. One of the six bile specimens examined was predominantly green, and in the chromatogram of this specimen a green substance was found to be the main pigment, with a peak at $18 \mathrm{ml}$., being followed by a small amount of diazo-negative yellow pigment. One other specimen had some green pigment which was eluted in the same position. It is possible that the presence of green pigment was due to post-mortem changes.

\section{Biliverdin}

A green band was also observed in some of the chromatograms of plasma pigments. The serum shown in Fig. 2 (neonatal haemolytic disease) has a small amount of green substance which followed the direct-reacting band and was eluted in the region of $30 \mathrm{ml}$. This green band was most prominent in the serum from an aged man suffering from a long-standing obstruction of the common bile duct due to carcinoma of the head of the pancreas. This patient's skin was reported to have a distinct blue-green hue in addition to a yellow? tint. This same green band was observed in the serum of one other case of obstruction.

While Lemberg and Legge (1942) have isolated biliverdin from erythrocytes, the identity of the green pigment in plasma has not yet been estab? lished, even though attempts have been made to estimate it (Larson, Evans, and Watson, 1947) on the assumption that it was biliverdin. It was there $\vec{\omega}$ fore of particular interest to determine whethes biliverdin behaved on the column similarly to the green band of serum, which is eluted after theos direct-reacting pigment at about $30 \mathrm{ml}$. A chroma i tographic examination of a specimen of puree biliverdin, kindly provided by Dr. J. E. Kench, is shown in Fig. 7. As it developed on the columntwo bands were clearly evident, both movin rapidly and close together. The leading band was much the more prominent of the two and waso eluted with a peak at $16 \mathrm{ml}$,, while the much fainter second band, not completely separated from the first, is shown as a peak at $18.5 \mathrm{ml}$. The actual peak of this band is probably at $19.5 \mathrm{ml}$ Both bands were green. It appears, therefore, tha biliverdin moves as fast, or faster, than the leading yellow band, and is probably different from the green band seen when serum extracts are studied, On the other hand, the position of the green band of bile is comparable to that of biliverdin.

\section{Adsorption on Denatured Protein}

It has been observed that when an ethanot extract of serum is prepared, as described above.".

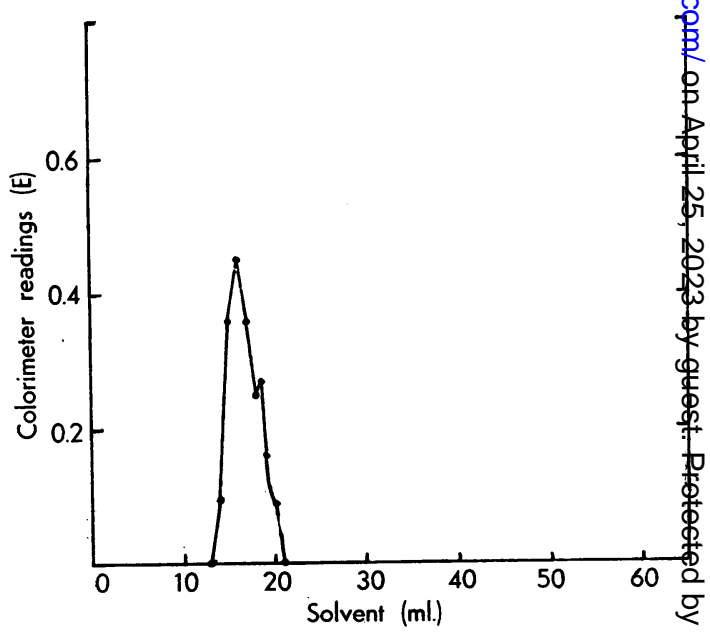

FIG. 7.-Chromatographic behaviour of biliverdin as shown b8 depth of colour (.—.) of the solvent coming off the column. 
the precipitate is far more pigmented in sera from cases of obstructive jaundice than in those from haemolytic jaundice. This was originally noted by van den Bergh. In view of the fact that the direct-reacting fraction is more polar than the indirect pigment it seemed difficult to understand why the latter was not adsorbed preferentially. In order to confirm that this was not the case the following exp?riment was conducted.

A specimen $(1 \mathrm{ml}$.) of serum from a case of obstructive jaundice was extracted by precipitating proteins with $2.5 \mathrm{ml}$. of alcohol, centrifuging, and removing the supernatant. The precipitate of protein was washed with alcohol, then with ether, and dried under reduced pressure. It was reconstituted with $1 \mathrm{ml}$. of $0.5 \%$ anhydrous sodium carbonate, and $50 \mathrm{mg}$. of crystalline trypsin (Armour) was added to hydrolyse the proteins. The whole was incubated for 16 hours at $37^{\circ} \mathrm{C}$., and afterwards unhydrolysed protein was precipitated by the addition of $2.5 \mathrm{ml}$. of ethyl alcohol. A considerable amount of bile pigment was set free from the protein which was dissolved by trypsin, and when examined chromatographically revealed a great predominance of the polar, direct-reacting pigment. This confirms the claim that the directreacting pigment is preferentially adsorbed on alcohol-precipitated, denatured protein.

\section{The Role of Proteins}

From time to time the difference between the direct and indirect reactions has been attributed to a linkage between bilirubin and protein, a possibility also considered by van den Bergh. According to this theory, in the indirect reaction alcohol, or some similar substance, is necessary to release bilirubin from plasma proteins. This possibility was to some extent excluded by the finding that in both direct- and indirect-reacting sera the bile pigment was protein-bound, and the same proportion was attached to albumin and $\alpha_{1}$ globulin, whatever the type of van den Bergh reaction (Gray and Kekwick, 1948). Nevertheless, the statement of Martin (1949) that $\alpha_{1}$ globulin "was the component responsible for the indirect van den Bergh reaction" has been interpreted by some (Drabkin, 1951) as applying to all sera giving an indirect van den Bergh reaction in any quantity. An alternative explanation, that a globin-bilirubin compound is the indirect-reacting pigment, and that albumin-bilirubin gives a direct reaction, has been put forward by Polonovski, Fiessinger, and Gajdos (1942) and supported by Watson (1946).

In view of the widely held opinion that the role of alcohol in the van den Bergh reaction is one of releasing protein-bound bilirubin, it is important to note that in the experiments described here, even after the action of alcohol and after the removal of alcohol and protein, the direct or indirect character of the serum reaction is still retained. However, the possibility that a small amount of protein was still retained in solution had to be examined. The feasibility of detecting the protein associated with pigment would depend on the amount present and the method used. According to Martin (1949) the molar ratio of bilirubin to albumin, at saturation, is slightly over 3 ; that is, $20 \mu$ of pigment are bound by a minimum of $1 \mathrm{mg}$. of protein. This amount of pigment (per $\mathrm{ml}$.) is exceeded in the peaks of Figs. 1 and 2. Samples of eluate, comparable with these, have been examined for protein, by precipitation with $10 \%(\mathrm{w} / \mathrm{v})$ trichloroacetic acid, and estimation of the nitrogen, under conditions in which less than $0.002 \mathrm{mg}$. of protein would be detected. None was found.

Two other lines of evidence reinforce the impression that the type of reaction has nothing to do with the bilirubin-protein linkage. If bilirubin is added to serum albumin, and the pigment is then extracted, as from serum, and run on a column, it behaves identically with bilirubin alone. Also, if the direct reaction were given by virtue of a link between protein and bilirubin as suggested by Lemberg and Wyndham (1936) and by Watson (1946), then the dissolution of the protein by trypsin hydrolysis would yield indirect-reacting bilirubin. It has already been shown that this does not occur. It may be concluded then that the directness, or indirectness, of the van den Bergh reaction is quite unrelated to linkage with protein.

The possibility that the direct or indirect character of the reaction was due to the presence of inhibiting or catalysing substances has been rejected by Coolidge (1940) after a study of the van den Bergh reaction of mixtures of sera. However, Gray and Whidborne (1947), who measured the rate of diazo colour development in various sera to which bilirubin had been added, thought that there might be a catalytic agent in some cases. In our experience no effect on the amount and movement of the two bands on the chromatography columns is produced by mixing the two types of pigment with sera or with tissue extracts, except for the retardation of bilirubin, which has been referred to already. The material which retards bilirubin has no effect on the movement of the direct-reacting pigment. One naturally occurring agent which can replace alcohol in the indirect reaction is bile salt. However, a chromatogram of 
sodium desoxycholate and bilirubin together is indistinguishable from one of bilirubin alone.

Various reports have stated that under certain conditions bilirubin may give a direct reaction. It does so in alkaline solution (Davies and Dodds, 1927 ; Griffiths and Kaye, 1930b; Gedigk and Gries, 1952). The effect of running alkaline material, probably a salt of bilirubin, on reverse phase columns has been investigated. Provided that the residual alkali is not in excess of the buffering capacity of the column, the pigment behaves in the same way as bilirubin, is eluted in the slow-moving band, and gives a van den Bergh reaction of the indirect type. This observation has its parallel in the experience of Harrop and Barron (1931) and of Thompson and Wyatt (1938), who found that in man after the intravenous injection of a direct-reacting alkaline solution of bilirubin the plasma gave an increased indirect reaction.

In view of the fact that all our attempts to make bilirubin behave as a fast-moving pigment on the chromatogram, and then to react directly, have been unsuccessful, the conclusion seems warranted that there are two types of pigment. The evidence is very strong that the indirect-reacting pigment is bilirubin, probably in association with another material which retards its movement on the column. The association of bilirubin with an alcohol-soluble material of serum has already been suggested by Hunter (1930). The nature of the direct-reacting material from serum is at present uncertain. Substances of this type have been prepared from gall-stones, as reported by Griffiths and Kaye (1930a), Griffiths (1932), and Fowweather (1932). These substances have been distinguished by their water solubility, and this contrasts with the chloroform solubility of the indirect-reacting pigment (Grunenberg, 1923). In this general respect there is agreement with the relatively polar character of the direct-reacting chromatography fractions and the less polar nature of the indirectreacting pigment.

No attempt has been made to define the characteristics of the polar, direct-reacting pigment in detail, nor to study its relation to bilirubin, with which it is probably interconvertible. From other experiments we are inclined to the view that the polar band from serum has two components, and these must be separated before their chemical nature and physiological behaviour can be investigated.

\section{Summary}

The bile pigments have been extracted from $\Rightarrow$ sera of patients with haemolytic and obstructive $\stackrel{\rho}{?}$ jaundice. By reverse phase chromatography they? have been separated into two types. The first is $\frac{\bar{c}}{\overline{5}}$ more soluble in water, and therefore moves more $\overrightarrow{\widetilde{\sigma}}$ rapidly on the column. It gives a direct van den $\mathrm{D}$ Bergh reaction. The second, more soluble in organic solvents, is eluted later. It reacts indirectly $\vec{O}$ in the van den Bergh reaction.

Both pigments, when prepared by chroma- $\overrightarrow{\vec{\omega}}$ tography, contain no protein. From this and other? evidence it is concluded that the nature of the van? den Bergh reaction does not depend on the splitting os by alcohol of a linkage with protein, but on the existence of two types of pigment.

The indirect-reacting pigment of serum is prob-궁 ably bilirubin. The nature of the direct-reacting material has not yet been established.

Necropsy bile contains several pigments, some of which do not conjugate in the van den Berghe test. A green pigment, behaving like biliverdin, $\omega$ has been found in bile. Green bands, which separate in the chromatography of serum extracts, do not appear to be due to biliverdin.

We are much indebted to Drs. C. G. Barnes, S. P. V. Sherlock, A. Paton, and C. M. Hoyle for providing us with serum from icteric patients, and to Drs. I. D. P. $\overrightarrow{\vec{B}}$ Wootton and W. E. Hunt, who supplied us with speci-J mens of necropsy bile. The specially treated kiesel-J guhr was prepared by Mr. C. R. J. Ruthven, to whomo we are very grateful.

\section{REFERENCES}

Bergh, A. A. H. van den, and Müller, P. (1916). Biochem. Z. . 77, 90 음 Cole, S. W. (1933). Practical Physiological Chemistry, 9 th ed p. 24. Heffer. Cambridge

Coolidge, T. B. (1940). J. biol. Chem, 132, 119.

Davies, D. T., and Dodds, E. C. (1927). Brit.J. exp. Path., 8, 316 윽

Drabkin, D. L. (1951). Physiol. Rev., 31, 345.

Fowweather, F. S. (1932). Biochem. J., 26, 165.

289, 261 .

and Whidborne, J. (1947). Biochem. J., 41, 155.

Griffiths, W. J. (1932). Ibid., 26, 1154.

- and Kaye, G. (1930a). Ibid., 24, 1400.

- (1930b). Brit. J. exp. Path., 11, 441.

Grunenberg, K. (1923). Z. ges. exp. Med., 31, 119.

. ges. exp. Med, 31, 119 . $N$

Harrop, G. A., and Barron, E. S. G. (1931). J. clin. Invest, 9, 5770

Howard, G. A.. and Martin, A. J. P. (1950). B. Brit. J. exp. Path., 11, 415 . King. E. J., and Coxon, R. V. (1950). Journal of Clinical Pathology

Larson, E. A., Evans, G. T., and Watson, C. J. (1947). J. Lab. cline Med. 32, 481 . Med., 32, 481 .
Lemberg, R., and Legge, J. W. (1942). Aust. J. exp. Biol. med. Sci.

and Wyndham, R. A. (1936). Biochem. J., 30, 1147.

Martin, N. H. (1949). J. Amer. chem. Soc., 71, 1230. Chim. biol., Paris, 24, 221.

Thompson, H. E., and Wyatt, B. L. (1938). Arch. intern. Med, $61 \stackrel{\text { D }}{\text { (1) }}$ 481 .

Watson, C. J. (1946). Blood, 1, 99. 